\title{
An Equality Paradox? The Northern European Case
}

\author{
Per Olaf Aamodt
}

\section{INTRODUCTION}

From an outsider perspective, the Nordic countries are probably regarded as similar to one another and unique compared to other regions. In particular, Nordic welfare states' policies, which have aimed to reduce differences in living conditions in general and establish conditions for 'education for all', have seen the Nordic countries establish themselves as a worldleading region in progress on equality and educational access. However, despite relatively low levels of inequality, comprehensive school systems, tuition-free education and generous economic student support, there is still a considerable degree of inequality in access to higher education. This apparent paradox is the topic of the present paper: how can we explain the limited success in achieving educational equality, even in what appear to be particularly promising conditions?

P. O. Aamodt $(\bowtie)$

Nordic Institute for Studies in Innovation, Research and Education (NIFU),

Oslo, Norway

e-mail: per.aamodt@nifu.no

(C) The Author(s) 2022

O. Tavares et al. (eds.), Equity Policies in Global Higher Education, Issues in Higher Education, https://doi.org/10.1007/978-3-030-69691-7_9 
The main purpose of the present paper is to focus on inequality in higher education in the Nordic countries. To do so, it is necessary to place these countries in a broader comparative context and to take a broad sweep of literature and prior research. The research results are based on different data and methodologies, and it is not possible to treat them in a strictly comparative way. In addition, most of the recent research is based on advanced statistical methods producing indicators which may be difficult to explain. Therefore, the paper mainly presents a narrative review of the results. Most research data come from single countries, but some comparative data exist. Only research covering Denmark, Finland, Norway and Sweden is included in the paper. Iceland is excluded since almost half of its students' study abroad.

In this chapter, I will try to answer three main questions based on a review of international research:

1. To what degree are the Nordic welfare states exceptional examples of equality in higher education?

2. Is there a Nordic model with strong equality similarities between the countries?

3. To what degree are the developments in the Nordic countries in line with the MMI and EMI theories?

In addressing the concept of 'equality in education' it is important to consider that this may be understood in several ways, as discussed by Amaral (this volume), and as is clear historically, with meanings shifting from: formal equality when education is no longer offered according to social status; resource equality, that is, entry into education should be independent of family economy; and equality of results, implying the introduction of compensatory measures (Hernes, 1974; Hernes \& Knudsen, 1976). Today, formal equality exists more or less on a global level; measures for resource equality exist in most countries to a varying degree and in different forms, while equality of results is less developed. The term 'equality of opportunity' is often used, but James Coleman, a leading sociologist, finds the term misleading, ' $\ldots$ because it suggests that equal educational opportunity, defined in something other than a purely formal (input) way, is achievable, while it is not. A proper formulation would use the term 'reduction in inequality' rather than 'equality' (Coleman, 1990). 


\section{Why Study Inequality in Education?}

Several supranational organisations have put equality in education on their agenda (Amaral, this volume), and educational inequality (especially by social class) has for many decades been a dominant topic of research. One obvious reason for this interest is that education is a positional good (Marginson, 1998) and important differences in living conditions (employment status, job satisfaction, income, political and organisational participation and health) are related to level of education. In their writings on social inequality in education in Sweden, Robert Erikson and Jan O. Jonsson list some other arguments against social inequality in educational enrolment (Erikson \& Jonsson, 1993, 1996).

Their first argument is that social inequality in educational enrolment is socially ineffective, resulting in a waste of talent, hindering processes where the 'right person ends up in the right place'. The rationale behind many of the school reforms in the Nordic countries since 1900 has generally been to increase the chances for the poor to be educated. The Human Capital theory, which was formulated around 1960 (Becker, 1964; Mincer, 1962; Schultz, 1961), gave new momentum to the policy, as a way to better utilize the talent reserves in the population; the same rationale underpinned many of the arguments for the expansion of higher education.

Unfairness, the second dominating argument against socially biased enrolment, is based on the premise that not everyone has the chance for an education according to her or his abilities. Class differences in educational attainment imply that children from different social classes do not have equal life-chances. Liberals and social democrats attacked the schools of the early twentieth century from this perspective, as drivers of the reproduction and maintenance of class divides, and several educational reforms have been motivated by this argument.

Social discord may result if children from different classes go to different schools, leading to reinforced class differences. Additionally, some have argued that children who would be expected to cooperate in their later working lives should not start by being separated into different schools. This may also lead to a lack of social cohesion.

Lack of representativeness. Others argue that it might be problematic if all people with higher education, holding leading positions in society, are recruited from a narrow social elite. Important decisions should be made by people who are representative of the population. Such arguments are mainly raised today about the representation of women, as well as 
various minority groups. These arguments have been important in the Nordic context, but are also relevant in a broader context.

\section{The Nordic Context}

The five Nordic countries are rather small, with populations of ca. 10 million (Sweden), 5.8 million (Denmark), 5.5 million (Finland and Norway), and Iceland with less than 350,000. Together, the region has about 27 million inhabitants.

The Nordic countries are usually characterised in terms of their high living conditions and high scores on international surveys of life satisfaction (Ramstedt, 2009). From a comparative perspective, income differences measured by Gini-coefficients are still small (OECD, 2016). There are several similarities and commonalities between the Nordic countries, but also substantial differences. With the exception of Iceland, the Nordic countries are situated close to each other, but their geography and history is still highly diversified, differences which also are important for the economy and industry.

Denmark is a flat fertile country with highly developed agriculture, Finland is dominated by forests, Norway is dominated by its long coastline and fjords and mountains and Iceland is dominated by arid volcanic fields as well as a long coastline. Sweden has the strongest industrial history based on iron, but industrial development has also been strong in Denmark, Finland and Norway. Fishery, and more recently fish-farming, is important in Iceland and Norway, and both these countries have strong energy resources from thermal and hydropower respectively. During the last 50 years, Norway in particular has had considerable income from oil and gas production (Fig. 9.1).

There is a range of similarities between these countries in terms of history, culture and political systems, and they have developed a close cooperation since 1945. But there are also significant differences. These variations in histories have complex influences on one of the central 'missions' of nation-states: the development and reform of a national education system. Denmark, Norway, Sweden and Iceland have been connected historically and culturally, and they belong to the same language family. People in Denmark, Norway and Sweden can easily communicate. Finland, on the other hand, has a very different language, but also has a Swedishspeaking minority. There are also significant historical differences. 


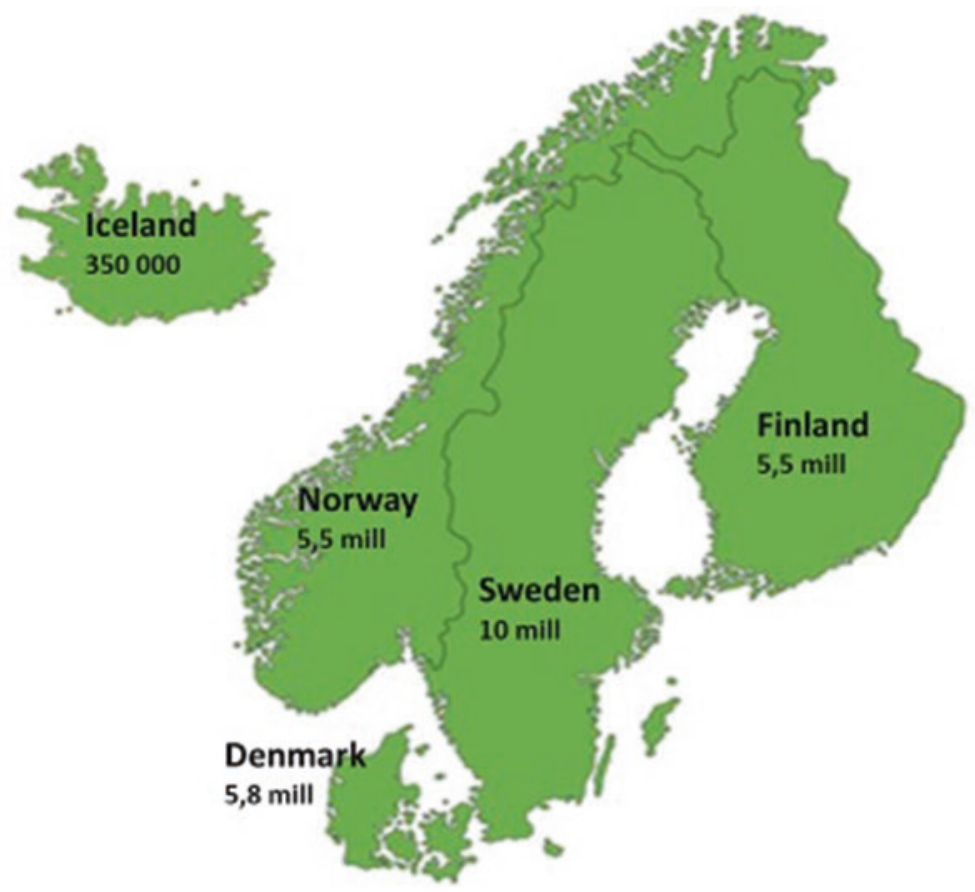

Fig. 9.1 Map of the Nordic countries

Denmark and Sweden have been independent monarchies since the middle ages, while Norway became independent from Denmark in 1814 and from Sweden in 1905. Iceland got its independence from Denmark in just 1944. Finland has had a turbulent history, alternatively occupied by Sweden and Russia, before being granted independence from Russia in 1917. Denmark, Finland and Norway were strongly affected by World War II, and had to start rebuilding their economy post-1945. In recent years, the five countries have chosen different paths in European cooperation: Finland, Denmark and Sweden are EU-members; Iceland and Norway are not.

During the nineteenth and twentieth century the Nordic countries developed their democracy and, in the post-war period, they have had a strong economic development. Denmark, Sweden and Norway were long dominated by social democratic governments, and all five countries 
developed welfare state systems. The welfare state model in the Nordic countries is important for understanding the development of their educational systems. Among others, Esping-Andersen (1990) distinguishes between three different welfare state systems: the liberal model (e.g., USA, Canada, Australia), characterised by targeted contributions to lowincome groups, and provision of typical welfare services via private actors; the conservative model (e.g., Austria, Germany, France and Italy), with typically less emphasis on market mechanisms than the liberal model, and marginal elements of distribution mechanisms based around traditional family patterns; and the social democratic model (the Nordic countries), characterised by redistribution policies and universalistic contribution mechanisms. The retention and ongoing development of relatively robust, universalistic welfare state policies has been widely argued to mark the Nordic region as something of an outlier from other European countries or Western democracies globally.

As in most other countries, higher education has expanded significantly in the Nordic countries, and student numbers are 20-25 times higher today than in 1950. There have been two large phases of expansion, the first in the 1960s, and the second in the 1990s and early 2000s. The first wave of expansion took place in a period of extended, stable economic growth and increasing demand for more skilled manpower, as well as of demographic growth due to the post-war baby-boom. The second expansion occurred in a time of economic stagnation (Börjesson et al., 2014) and started earlier in Sweden than in the other countries. Due to its small population, Iceland has not been able to offer higher education for all, despite rising demand, so almost half of its students study abroad.

\section{Educational Policies in the Nordic Countries}

From the mid-nineteenth century, the school systems were reformed in the Nordic countries (Norway-Tønnesen, 2011), (Denmark-Gjerløff \& Faye Jacobsen, 2014) (Sweden-Erikson \& Jonsson, 1996); these waves of reforms continued for almost 100 years. The reforms had their origin in the modernisation and democratisation of society (Tønnesen, 2011) and were also based on the idea that it was unfair that a person's life chances should be dependent on the status of the family he/she was born into (Erikson \& Jonsson, 1996). During these reforms, parallel school systems, with different schools for rich and poor, were gradually replaced by a comprehensive school. The last major reforms in compulsory 
schooling took place in the 1950s-1960s when lower secondary education was included in the nine years of compulsory schooling, and hence abolished the selection between primary and lower schooling. Continuous reforms of the Nordic school system, over more than 150 years, gradually widened the entry into higher education, but did not lead to any immediate expansion in higher education enrolment. The school reforms were nevertheless an important prerequisite for the expansion of higher education that would start after World War II.

Educational policy in the Nordic countries is closely connected to the social democratic welfare state policy. Most schools and tertiary education institutions are public and, as in Germany, there are no or very low tuition fees in higher education. Unlike most other countries, the introduction of tuition fees in tertiary education is not even part of the political agenda at the moment. Equality arguments in the Nordic countries are still robust and widely accepted: fees are seen as unfair, leading to social differences in higher education attendance. In many other countries, such arguments have been inverted: it is socially unfair that families with ordinary incomes should contribute to pay for higher education, when the majority of its students come from well-off families, and the same students can look forward to high incomes after graduation. This debate in itself reveals a great deal about how complex and contested the notions of 'fairness', 'justice' and 'equality' become when they are used to support reforms and interventions in higher education systems.

In addition to tuition-free higher education, prior to 1950 the Nordic countries established state-run student support systems. Student support in the Nordic countries is offered through a combination of loans and grants and is intended to make students independent of family income. Student support varies among the Nordic countries both in the balance between loans and grants and in other regulations, but all of them support students economically during their studies, and also provide incentives or impose restrictions that encourage students to complete their studies without significant delay. Danish student support has the highest proportion given as grants and is therefore considered to be the most favourable for students, but all the systems can be characterised as generous from a global perspective.

It is easy to see how the Nordic model of education is closely linked to the social democratic welfare state model in being universal (not needsbased). Students are regarded as independent individuals, and financial support is given directly to the student. The student's family is not 
expected to contribute, as is the case in countries with a conservative welfare model. A comparative study covering the Czech Republic, England, Germany, the Netherlands, Norway, and Spain shows that while England, Spain and Norway allocate all financial support directly to students, Germany and the Czech Republic allocate a substantial part to their parents (Schwarzenberger \& Opheim, 2009), which is in line with the conservative welfare state model. In Germany, for example, only some students receive direct financial support, which is dependent on their parents' income. A high proportion of Norwegian students live away from home, and they fund a larger proportion of their cost of living from paid work during their studies. The total public share of support to Norwegian students is therefore not especially high. The universalistic principle of the Norwegian model is also illustrated by the absence of means-testing: support does not vary according to social background. This is a major contrast to England, where most of the economic support is allocated to students from low and medium income backgrounds.

This is not to say the higher education systems in the Nordic countries are essentially the same. They differ from one another and have changed over time, in particular in how the HE sector is structured and the presence of binary divides or other ways of distinguishing academic and vocationally oriented higher education. In Denmark, higher education is carried out in business academies (offering short-cycle programmes), university colleges (offering medium-cycle programmes) and universities (offering long-cycle programmes). In Finland, there are 13 universities and 23 universities of applied sciences in the Ministry of Education and Culture sector. Higher education institutions are mainly multi-field institutions. In Norway, higher education was organised in a relatively clear binary model (universities and university colleges) until the mid-1990s. After several reforms, upgrades and mergers, there are now 10 universities (enrolling two thirds of all students) and six specialised universities (enrolling the rest). The university sector has changed from four 'traditional' universities to more hybrid institutions. There are only five university colleges remaining, of which two can be expected to be awarded university status within a few years. In Sweden, the majority of higher education and research is carried out at the 14 state universities and 17 state university colleges. First and second cycle (undergraduate) education is given at an equivalent level at university colleges and universities. 


\section{Analytic ApProach}

For a long time, it was expected that the expansion of higher education would level out social inequalities in access and outcomes. However, the research presented in this paper shows that this substantial expansion has only led to marginal equalisation. This confounding pattern must be considered if we continue to aim for, and reform in the name of, greater equality. Boudon (1974) expected that once higher education attendance reached a certain high level among the upper classes and the attendance of lower classes continued to increase, inequality would be reduced. As presented in Amaral (this volume), Raftery and Hout (1993) introduced the theory of 'maximally maintained inequality' (MMI), which hypothesises that the gap between the participation rates of the upper and lower classes will only diminish when the participation rate in the upper classes approaches saturation. Lucas (2001) elaborated this further into 'effectively maintained inequality' (EMI), distinguishing between institutions and study programmes, stating that privileged groups will seek out specific prestigious study options once the advantages of reaching a certain level no longer apply.

The MMI and the EMI models are good illustrations of the patterns of inequality, but do not really explain how these patterns are shaped by individual preferences and acts, as well as contextual factors. Inequalities in higher education have their origins in earlier stages in the educational system as well as the entrance points to higher education (Baptista, Sin and Tavares [this volume]). Efforts to unpack and map the multiple factors for inequality have proliferated. Mare $(1980,1981)$ launched a model of transition points in the educational career. Boudon (1974) introduced the concepts of 'primary effects' and 'secondary effects'. Primary effects (also termed ability-effects) describe the linear relation between parental social status and children's measured ability, as well as school grades, whether based on genetic or socio-cultural factors. In most social research, the genetic factor is not denied, but few attempts are made to distinguish between what are inherited personal abilities, and what are the results of the influence of the family or school.

Secondary effects (or choice-effects) are active when students from different social classes make different educational choices, even when their school achievement is at the same level (Aamodt, 1982; Erikson \& Jonsson, 1996; Hernes \& Knudsen, 1976; Jackson et al., 2007). At each transition point in the educational system, when students have to make a 
choice, whether to continue or not, or to enter academic or vocational tracks, these secondary effects tend to lead children from different social origins to make different choices. The transitions between levels in educational systems are also affected by intake regulations, usually based on grades as well as the strength of competition among applicants. Both the choices made and the selection mechanisms in place lead to increasingly social-biased enrolment patterns at each step. Jackson et al. (2007), based on a study of transitions into A-level courses in England and Wales, conclude that it is a serious error to ignore Boudon's distinction between primary and secondary effects.

These primary and secondary effects are well-illustrated by recent Norwegian data (Hansen, 2019): Among pupils with the best grades, almost all continue to academic upper secondary education, regardless of family background. Among those who get the lowest grades, a considerable proportion of students from the upper classes continue, but almost none from the lower classes. And among students with average grades, 90 per cent of students from the higher classes continue to academic upper secondary education, but only 50 per cent from the lower classes. Students from lower classes tend to choose vocational upper secondary schooling. Furthermore, students from upper classes have a higher chance of completing and getting better grades in upper secondary education, and also in the transition from upper secondary to tertiary education. The totality of these many decisions and selection patterns combine to result in the remarkable persistence of tendencies for family background (class) to shape how far, and where, individuals in any given educational system eventually end up.

It should be added that selection in the education system is not unintended or an anomaly. One of the roles of the school system is to contribute to the allocation of the young generations into different occupations based on merit rather than on inheritance. This role, where schools are understood as creating and potentially recreating social structures in various ways, again underpins the centrality of debates about what educational equality is and how far it can or should be achieved. A range of theories has been developed to clarify this role of schools and explain why there are socially based inequalities in education. Boudon (1974) divided these theories into three categories: value theory, culture theory and social position theory. The presentation of these theories is partly based on Helland (2004).

The value theory was developed in the 1950s and is based on the assumption that social differences in education arise because youth from different 
classes value education differently and that youth form lower classes act against their individual interests. Boudon (1974) rejects the value theory since value-based actions are traditional and not purpose-rationale. However, Grøgaard (1997) finds evidence for class-specific values that guide educational choices.

The culture theory is mainly focused on differences in school achievement which are thought to be related to cultural differences. Bernstein (1969) stated that children from upper classes acquire a more advanced language which is favourable within the school. The cultural theory of Pierre Bourdieu (Bourdieu \& Passeron, 1990) describes the mechanisms behind social reproduction using the concepts habitus and cultural capital. The upper classes have acquired both a certain habitus and cultural capital which is favourable for succeeding in the educational system.

The social position theory (Boudon, 1974) is often seen as an opposition to Bourdieu's theories. It suggests that choices made in education are based on relativistic comparisons between costs and benefits of education and education aspiration and ambitions which are assessed from the perspective of one's social position; this explains, among other things, the tendency for young people to aim for at least as much education as their parents. According to Boudon (1974), the culture theory may contribute to the understanding of the primary mechanisms that lead school achievement to differ between social classes, while the social position theory may explain the secondary effects. The social position theory was later developed towards a pure theory of rational choices, leaving out cultural elements for example, by Goldthorpe and Breen (2000). One of the important concepts within this theory is risk aversion: the concern about downward social mobility is stronger among youth from higher classes than is the wish for upward mobility among lower classes.

All of these theories may contribute to the understanding of inequality, but it is difficult to accept that transitions in education are not based on some sort of rationality, even if this is limited due to a lack of information about future consequences (Elster, 1989). The title of Diego Gambetta's book (1987) Were They Pushed or Did They Jump? is illustrative of the dilemma around rational choice interpretations of school selection and transitions.

Erikson and Jonsson (1996, p. 55) sum up explanations of social inequality in education as follows: 
1. Academic performance is better among children from higher social classes (genetic or culture)

2. Actual educational costs are higher for lower classes, primarily affecting transitions to higher education

3. Actual probabilities of success (at a given achievement level) are higher, the higher the parents' education, help and support during school

4. Perceived benefits of education are greater for children from higher classes, because the negative value they place on downward mobility outweighs the positive value of the corresponding social ascent for children from lower classes

5. Perceived probabilities of success are lower for children from lower classes at the earliest educational choice

Of these points, Erikson and Jonsson regard the first to be the most important.

The possible explanations for inequality in higher education presented above have their focus on individual ability and actions, but these do not operate in a vacuum, but depend on educational systems, national policies on education and, in general, on economy and class structure. The different welfare state models presented above can be related to funding models of higher education and student support models. The higher education model in the Nordic countries differs considerably from most other European countries and the US, being free of tuition and offering generous public student support. In addition, there is less of a difference in prestige between higher education institutions in the Nordic countries.

\section{Higher Education in the Nordic Countries from a Comparative Perspective}

Comparing enrolment trends and patterns between countries is complicated, partly due to the lack of genuinely comparative data, but also as the topic may be approached and understood in several ways. It also raises new questions: Which countries should be compared, and which educational levels should be included? Are we looking at enrolment patterns in a specific period or trends over time? How can we make sense of changes in educational access and attainment when social structures and stratification 
are changing, too? How do we account for changes in higher education systems when we look at these trends?

We will first present a small (but important) sample of comparative research. In these comparisons, Sweden is the only Nordic country represented. As one of the first comparative projects in this field, the book by Shavit and Blossfeld (1993) has long been a point of reference. The book is based on comparative data from 13 countries: USA, the Federal Republic of Germany, the Netherlands, Sweden, England/Wales, Italy, Switzerland, Taiwan, Japan, Poland, Hungary, Czechoslovakia and Israel. In all countries, except Taiwan, Japan, and England/Wales the data included both women and men. In all countries, cohorts over a long time span were studied, comprising those born from around 1900 until the 1960s. The book does not focus specifically on higher education, as transitions between all major levels were studied.

Some of the main conclusions in the book are:

- In all thirteen countries there was a marked educational expansion during the observed period.

- In Sweden and the Netherlands there was a clear overall decline in the effect of social background, while the expansion did not lead to equalisation in the other countries.

- The effect of social origin was strong at the beginning of the educational career and declined for later transitions.

- In the countries where data were available for both men and women, there was a marked reduction in gender differences.

- The impact of educational reforms on educational stratification seemed to be negligible.

Following the book from Shavit and Blossfeld (1993), a large number of articles and books were published which responded to these claims. Some of these contributions contested the conclusions of Shavit and Blossfeld, based on more recent data and more sophisticated statistical methods (Breen et al., 2009; Breen \& Jonsson, 2005). Arum et al. (2007) also conducted a comparative study, mainly directed at higher education, covering many more countries than Shavit and Blossfeld (1993). They found that in four countries (Japan, Korea, Taiwan and Sweden) inequality in the eligibility for higher education had declined, and in Italy and Israel the inequalities in the transition from secondary to tertiary 
education had declined. In the rest of the countries, inequality was more or less stable or even increasing.

Breen et al. (2009) found that, in general, inequality had declined between 1950 and 1975 and, at the same time, the disadvantaged classes tended to shrink. Furthermore, they found that the transition from primary to secondary education had been equalised and, since the inequalities in transition from secondary to tertiary education remained unchanged, enrolment to tertiary education had become more equal.

\section{Inequality in the Nordic Countries}

Studies in educational inequality have a long history in the Nordic countries, especially in Sweden, where Gunnar Boalt (1947) was a pioneer, using survey data. After 1970, all Nordic countries developed population register statistics which increased research possibilities significantly, since transitions over educational careers could be followed for entire cohorts.

Erikson and Jonsson (1996), in their conclusions, stated that changes in educational inequalities were difficult to analyse and that results for Sweden may be interpreted in different directions. But they concluded that equalisation in Sweden, after all, had been quite substantial. Inequalities decreased between 1930 and 1970, while the pattern was stable before and after this period. In a more recent study, Jonsson and Erikson (2007) concluded that there was little evidence to support tertiary education expansion as an effective means for educational equalisation. In certain conditions, if expansion is combined with lowering very high admission requirements, some degree of equalisation may occur. Additionally, expanding tertiary education by establishing new institutions with lower academic status may lead to equalisation, but also to increasing stratification within the tertiary sector.

Finnish data covering higher education enrolment from 1970 to 2000 (Kivinen et al., 2007) indicates a development towards decreasing inequalities in Finland. The odds ratio for differences in participation in university education between those from academic and non-academic families shrank from 19 to 8 , and this reduction is stronger for men than women. During these three decades, Finnish higher education was transformed from an elite system into a mass system. At the start of this period, the system favoured males with background in academic families, whereas today women are in the majority and the effect of family background has weakened. 
Based on register data from Statistics Norway for the cohorts born from 1951 to 1960, Aamodt (1982) analysed transitions after compulsory schooling and enrolment in higher education in 1974 and 1978. Comparisons were also made with previous Norwegian research (Vangsnes, 1967) covering the period from 1951 to 1963 . The analyses showed that there had been a strong expansion in the numbers of students eligible for entry into higher education by completing the academic track in upper secondary education (matriculation examination). Comparisons between socioeconomic groups based on the father's occupation showed that in the social group 'superior employees, professionals and teachers', the percentage completing academic upper secondary education increased from 47.9 to 62.1 during the analysed period between 1951 and 1978, while in the social group 'workers and foremen' the percentage increased from 3.5 to 20.8. In other words, differences were considerably reduced.

Transition to university from the academic upper secondary education five years after graduation could only be observed for the 1951 to the 1974 cohort. The differences between social groups in this transition were considerably smaller than in the matriculation examination completion mentioned above. In the 1974 school leaving cohort the percentages were 54.0 and 34.3 for the two social groups, 'superior employees, professionals and teachers' and 'workers and foremen' respectively. This shows that most of the social inequality in university enrolment was established already before students left upper secondary education. But while recruitment to academic upper secondary education became less socially biased during the observed period, the differences increased in the transition to university. In the social group 'workers and foremen' the percentage increased from 30.9 in the 1951 -cohort to 34.3 in the 1974-cohort, whereas the increase was from 43.9 to 54.0 in the social group 'superior employees, professionals and teachers'. In other words, there are indications that during the massification of education, selection moves up one level.

Enrolment in the non-university sector is less socially biased than enrolment in universities. Measuring family effect by father's education, 32.2 per cent of the relevant age group having fathers with a university degree were enrolled in a university in 1975 , against 2.5 per cent if the father had only compulsory education. In the non-university sector, the figures were 9.6 and 3.0 , respectively.

In the early 1990s, Norway experienced a strong increase in applicants and stronger competition for entry into higher education due to high 
youth unemployment, and it was a concern that this would lead to increasing social inequality. A study based on register data for 1980 and 1990 showed that this was not the case; on the contrary, inequality had decreased in higher education as a whole, especially in the non-university sector, while the enrolment pattern in universities had been stable (Knudsen et al., 1993).

Like Knudsen et al. (1993), Hansen (1999) showed an increasing social segmentation between different tracks in Norwegian higher education. In her study, based on register data for the age cohorts born between 1962 and 1973, she made a distinction between university colleges offering mainly short vocational education (e.g., nursing, teaching, undergraduate engineering), open university programmes, and selective elite university programmes (law, medicine, dentistry, veterinary medicine, graduate engineering, business administration and architecture). While the two first options had expanded considerably in the studied period, the third had a more stable enrolment. As expected, enrolment differences by social class had been reduced in the university college sector, but the expansion of the open university programmes had not led to any trends towards equalisation. And finally, the strong social differences in enrolment of the elite programmes had continued. Family income had an additional effect on enrolment probabilities and was strongest for the choice of elite education.

More recent results are presented in Fig. 9.2 which shows the percentage of 19-24 year olds enrolled in higher education, by parents' educational level. While the participation rate among those who have parents

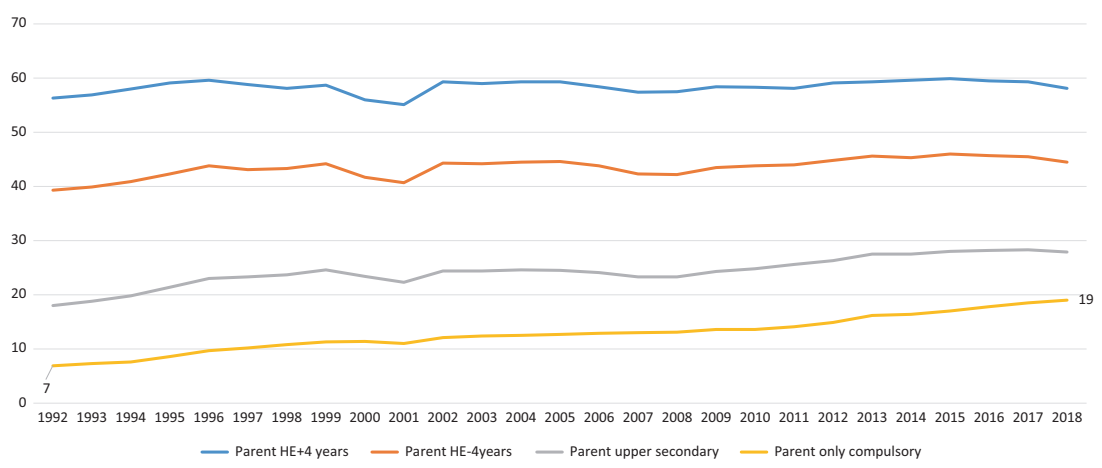

Fig. 9.2 Percentage of 19-24 year olds in Norway enrolled in higher education by educational level of parents. 1992-2018 
with more than four years of higher education is more or less stable from 1992 to 2018 , the participation rate among those whose parents have only compulsory education more than doubled, from 7 to 19 per cent. The ratios between the two groups have decreased from $8: 1$ to $3: 1$, indicating a clear trend towards decreasing inequality, but still the difference is large. From 1992 to 2018, the percentage of the parents' generation (40-49 years) with higher education in total increased from 23 to 44 per cent, while those with only compulsory schooling went down from 25 to 16 per cent.

Recently, Thomsen (2015) conducted a study based on register data from Denmark on educational status for the entire population aged 25 for each year from 1984 to 2010 . He used information about parents' highest education level and income to measure cultural and economic capital respectively. He furthermore classified Danish higher education programmes into four types: selective liberal arts university programmes, selective applied university programmes, non-selective liberal arts university programmes and non-selective applied university programmes. During the period from 1984 to 2010 , higher education expanded significantly, and attendance rates increased for almost all groups and study programmes. In 1984 sons of higher educated parents were about four times more likely to attend higher education than sons of lower educated parents were, and in 2010, this ratio had fallen to $3: 1$. The corresponding ratio for daughters was lower in the whole period and only 2:1 in 2010 . While participation rates have become more equal between sons and daughters of parents with high or low education, there is a slight tendency towards the opposite development when comparing family income. Thomsen concludes that when looking at access to higher education in general, culturally privileged groups (children with higher-educated parents) have not maintained their relative advantage. Inequality has, however, been maintained by the economically privileged groups, but the level of inequality is much lower. Furthermore, Thomsen (2015) found clear disparities in participation ratios in different types of programmes; inequality was strongest in access to selective liberal arts programmes, where students with higher-educated parents had 8-9 times higher attendance rates than students with lower-educated parents. And while the non-selective programmes moved towards less inequality from 1984 to 2010 , inequality in the access to the selective liberal arts programmes was still high, and even slightly increasing. These findings support those of Hansen (1999) arguing that expansion has led to reduced inequality in higher education 
as a whole, due to the channelling of students from lower-educated families towards less prestigious programmes.

In the comparative research contributions presented in the previous section, Sweden is alone in representing the Nordic countries. A Nordic model has often been taken for granted, with similar enrolment patterns as well as levels of educational inequalities. To represent the 'Nordic model', Sweden has almost exclusively been used as a proxy for the Nordic countries. Furthermore, it has proven to be difficult to make comparisons between the Nordic countries based on previous national studies because of differences in time periods, operationalization and methods. Thomsen et al. (2017) therefore tried to address these research gaps in comparing higher education attendance by social origin, by setting up a truly comparative database covering Denmark, Finland, Norway and Sweden. They drew data from national administrative registers, classified all variables in the same way, used the same time periods and applied the same methods and models. Their article is therefore the first full-scale comparison of changes in the four Nordic countries across several decades.

Their starting point was that the Nordic higher education systems are embedded in the social democratic welfare state model, as presented above, characterised by universalist policies aimed at reducing inequalities and increasing opportunities. An overview of the higher education systems in the four countries, however, shows a number of differences in both the institutional landscape and the degree structure, even if the systems have converged after the Bologna process.

Thomsen et al. (2017) conducted their study by implementing three models: First, they focused on the overall higher education participation, second, they turned their attention to the upper tertiary level (which is not identical with university), and third, they looked at differences by study programmes. Contrary to the general impression of strong similarities between the Nordic countries, they found substantial differences in the enrolment pattern of sons and daughters from families with high and low education between the four countries. There were, so to speak, no signs of a 'Nordic model of higher education', as social inequalities in participation patterns differed, with Finland and Sweden at the extremes. This means that using Sweden as a proxy for the Nordic countries is problematic. Looking at changes in higher education generally, inequality in Finland and Norway was reduced from 1985 to 2010 in tandem with expansion, while Denmark had a more modest development. In Sweden, at the other end, there is no sign that expansion closed the gap in higher education 
between students from families with high and low education (this is in line with Jonsson \& Erikson, 2007). The stable level of inequality in Sweden may be related to the fact that the Swedish level of inequality was initially at a lower level than in the other Nordic countries in 1985.

There are great variations in inequality between educational fields, but enrolments in most fields in the Nordic countries equalised from 1985 to 2010. However, the most prestigious professional university programmes, such as law and medicine, still favour socially privileged students, even if the social gap has been narrowed in Finland and Norway. Hence, all Nordic research contributions presented above support the EMI model (Lucas, 2001).

\section{Discussion}

It is one of the most consistent findings in social science that those students who come from families of high social status, whether economic or cultural, are more strongly represented in higher education than other students. This class bias has long historical roots and still persists in spite of the massive increase in higher education enrolment worldwide since the 1950s. The picture is, however, less consistent when it comes to the question of changes over time and differences between countries. This should not be a surprise: it is far more complicated to conduct comparative social research between countries and over time-and hence even more difficult to analyse differences in trends between countries. Furthermore, researchers use different types of data, methodology, time periods and theoretical approaches.

It was long taken more or less for granted, based on the book of Shavit and Blossfeld from 1993, that in most countries there were no signs of equalisation, but that the Netherlands and especially Sweden deviated from this general picture with a significant tendency towards equalisation. Later research contested these conclusions, and most recent research has concluded that there have been significant movements towards decreasing inequality in many countries. But still, the signs of equalisation are less visible than the remaining differences.

Our first research question was: To what degree are the Nordic welfare states exceptional examples of equality in higher education?

In the examples from broad comparative research presented in this chapter, only Sweden is included, and the findings of both Shavit and Blossfeld (1993) and Arum et al. (2007) show that Sweden is among the 
countries with the lowest inequality. Within the Nordic region, however, Sweden is the country that has reduced inequality the least, suggesting that the other Nordic countries have made even greater progress than Sweden towards equality in higher education participation. Although enrolment in higher education both in Sweden and in the other Nordic countries is still far from being equal between social groups, one may tentatively argue that the Nordic countries stand out globally in the progress they have made. Even if the general welfare state policy and the higher education systems in the Nordic countries may be regarded as favourable for reducing inequality, other countries with different systems and policies have moved in the same direction.

Our second research question was: Is there a Nordic model with strong equality similarities between the countries?

Recent comparative research on the Nordic countries (Thomsen et al., 2017), covering the period from 1985 to 2010, showed considerable differences between the four Nordic countries both in levels of inequality and in changes over time. While Finland and Norway have developed towards reduced inequality, the changes in Denmark are more modest, while the situation in Sweden is stable. These differences may be due to differences in policies and higher education systems, and that the starting situation in Sweden was more equitable.

Our third research question was: To what degree is the development in the Nordic countries in line with the MMI and EMI theories?

Enrolment patterns in the Nordic countries clearly support the theory of maximally maintained inequality (Raftery \& Hout, 1993) and the theory of effectively maintained inequality (Lucas, 2001). As higher education has moved from a privilege for the few to comprising close to half of the age groups, and also the institutional structure has changed with the establishment of less prestigious higher education institutions beside universities, many researchers have shown that these new sectors have a more 'democratic' enrolment than the universities. This has, on the one hand, led to a certain equalisation of higher education as a whole. However, at the same time, the upper classes have kept their position at universities and to an even higher degree in the most prestigious and selective programmes like law and medicine. This has resulted in a stronger segmentation in enrolment between types of institutions and study programmes: entry into tertiary education in general has been equalised, but inequality is now present in the selection into prestigious institutions and study programmes. 
Some of the equality differences between the Nordic countries may be related to differences and changes in the higher education institutional structure. All Nordic countries have developed binary systems, establishing university colleges as alternatives to universities. However, this development happened in different stages: in Norway university colleges were established in 1970, in Finland in the early 1990s, and in Denmark in 2007 (Börjesson et al., 2014). There have been several national reforms and today, for example, in Norway, almost all former university colleges have been awarded university status or merged with a university. It is, however, not possible to prove a strict relationship between higher education systems and reforms. Compared to, for example, the USA, UK and France, there are less prestige differences between universities in the Nordic countries, but a relatively clear distinction between universities and university colleges exists.

As highlighted above, inequality in access to higher education is to a large degree a result of achievements and choices made in earlier stages of schooling. The PISA survey from 2015 shows that in Finland, Denmark and Norway, together with Japan, Estonia, Canada and Australia, the relationship between social class and PISA scores in natural sciences is weaker than in other countries. In Norway, 8 per cent of the variance in achievement may be related to socioeconomic background against 20 per cent in France (Kjærnsli \& Jensen, 2016). This may suggest that access to higher education in the Nordic countries is relatively equal between different social classes, even if this is difficult to prove empirically.

This chapter focuses on inequality by social class and parents' education, not on gender, geography and ethnicity. It is, however, remarkable that while social class differences persist, the participation pattern by gender has changed considerably in most countries. From being strongly male-dominated in the 1960s, today women are the majority in most countries. The development in Norway is probably relatively representative. As late as 1971, only 30 per cent of the student population was female; today it is 60 per cent. Changes in enrolment in the elite professional university programmes is especially visible. In 1964 women made up 8 per cent of law enrolments and 17 per cent of medicine. Today female students are the majority in both law and medicine with 65 and 69 percent, respectively. Today, only technical programmes are maledominated.

When comparing country differences and changes in social class differences in higher education participation over time, one should take into 
consideration that class structure and the educational level of parents differ between countries and over time. The most visible change is the strong increase in the educational level of the parental generation. The percentage of parents with higher education has increased strongly during educational expansion, and the percentage of those with only compulsory schooling has gone down; in the same period, both the farming populations and the number of industrial workers have been reduced. This must obviously have changed the effect on participation by social origin, but we will leave the answer open on how this has happened.

According to Marginson $(1998,2004)$, the value and attractiveness of education is related to the benefits of education later in life, especially for employment and social status. This relationship varies, not only between type of institutions and study programme, but also between countries. Since there are relatively small income differences in the Nordic countries as measured by Gini-coefficients, the relative value of higher education in terms of economic outcomes is lower than in many other countries. In spite of this, higher education is still attractive among the youth in the Nordic countries. Relatively low income advantages from higher education may also affect the relative economic benefits of a prestigious higher degree versus an undergraduate professional degree in for example, nursing and social work. How this affects inequality in enrolment is a potentially interesting research topic.

\section{Policies for Equalisation}

National educational systems vary between countries, since they reflect different cultures, history and political profiles, and there is probably no universal agreement about the most efficient policy to reduce inequalities. However, based on recommendations from the OECD report on equity (Field et al., 2007, p. 9) and Erikson and Jonsson (1993), the following suggestions may be formulated:

- Due to the strong impact of school achievement in primary education, early childhood education should be given priority. It is important to support learning so that as many students as possible reach a satisfactory performance level. Special support should be given to students who fall behind and their families. Year repetitions should be reduced. 
- Children who perform well in compulsory school should be encouraged to continue into the academic tracks in secondary schools. This may be a dilemma since the best possible vocational options should also be available.

- One should limit early tracking and postpone selection.

- Choice of schools should be managed in a way to avoid socially segregated schools.

- In upper secondary education, one should remove dead ends and prevent dropout. Second chances should be offered.

- Entry regulations in the transition between levels of education, as much as possible, should be based on objective criteria.

- Access to higher education should be open for students from all upper secondary programmes, possibly facilitated through specific courses.

- Higher education should give access to all who have obtained the formal entry qualifications.

- A generous student support system should exist, based on a combination of loans and grants. Indirect support for cost of living may supplement direct economic support to students.

Due to country differences in economy, class structure, general policy as well as in educational systems and educational policies, the suggestions for equitable education presented above are probably not equally relevant in all national contexts. We see a number of differences and similarities in enrolment patterns across national systems; for instance, there is a relatively diverse pattern between the four Nordic countries. Nevertheless, these suggestions reflect some guiding principles which should be considered in policy development.

\section{REFERENCES}

Aamodt, P. O. (1982). Utdanning og sosial bakgrunn. (Education and Social Background). Central Bureau of Statistics, Social and Economic Studies no. 51. Arum, R., Gamoran, A., \& Shavit, Y. (2007). More Inclusion Than Diversion: Expansion, Differentiation and Market Structure in Higher Education. In Y. Shavit, R. Arum, \& A. Gamoran (Eds.), Stratification in Higher Education. A Comparative Study (pp. 1-35). Stanford University Press.

Becker, G. (1964). Human Capital: Theoretical and Empirical Analysis with Special Reference to Education. University of Chicago Press. 
Bernstein, B. (1969). Social Structure, Language and Learning. In P. D. Cecco (Ed.), Language, Thought and Learning. Holt, Reinhard and Winston.

Boalt, G. (1947). Skolutbildning och skolresultat för barn ur olika sambällsgrupper i Stockholm. Volum 7 av Monografier utg, av Stockholms kommunalförvaltnining. Norstedt.

Börjesson, M., Ahola, S., Helland, H., \& Thomsen, J.-P. (2014). Enrolment Patterns in Nordic Higher Education, ca. 1945 - 2010. Institutions, Type of Education and Fields of Study. NIFU Working Paper 15/2014. NIFU.

Boudon, R. (1974). Education, Opportunity, and Social Inequality. Changing Prospects in Western Society. John Wiley \& Sons.

Bourdieu, P., \& Passeron, J. C. (1990). Reproduction in Education, Society and Culture (Vol. 4). Sage.

Breen, R., \& Jonsson, J. O. (2005). Inequality of Opportunity in Comparative Perspective: Recent Research on Educational Attainment and Social Mobility. Annual Review of Sociology, 31, 223-243.

Breen, R., Luijkx, R., Müller, W., \& Pollak, R. (2009). Nonpersistent Inequality in Educational Attainment. American Journal of Sociology, 114(5), 1475-1521.

Coleman, J. S. (1990). Equality and Achievement in Education. Westview Press.

Elster, J. (1989). Nuts and Bolts for the Social Sciences. Cambridge University Press.

Erikson, R., \& Jonsson, J. O. (1993). Ursprung och Utbildning. Social snedrekrytering til högre studier. SOU 1993:85. Utbildningsdepartementet.

Erikson, R., \& Jonsson, J. O. (Eds.). (1996). Can Education Be Equalized? The Swedish Case in Comparative Perspective. Social Inequality Series. Westview Press.

Esping-Andersen, G. (1990). The Three Worlds of Welfare Capitalism. Polity Press.

Field, S., Kuczera, M., \& Pont, B. (2007). No More Failures: Ten Steps to Equity in Education. OECD.

Gambetta, D. (1987). Where They Pushed or Did They Jump? Individual Decision Mechanisms in Education. Westview Press.

Gjerløff, A. K., \& Faye Jacobsen, A. (2014). Da skolen blev satt $i$ system. Dansk skolehistorie (3). Universitetsforlaget.

Goldthorpe, J. H., \& Breen, R. (2000). Explaining Educational Differentials: Towards a Formal Rational Action Theory. In J. H. Goldthorpe (Ed.), On Sociology. Numbers, Narratives, and the Integration of Research and Theory (pp. 182-205). Oxford University Press.

Grøgaard, J. B. (1997). Sosial bakgrunn - et mangehodet troll. Hvorfor har sosial bakgrunn så stor betydning for gutters utdanningsvalg? Et forsvar for verdiforklaringen. .

Hansen, M. N. (1999). Utdanningspolitikk og ulikhet. Rekruttering til høyere utdanning 1985-1996. Tidsskrift for Samfunnsforskning, 51(1), 101-133.

Hansen, M. N. (2019). Sosiale ulikheter $i$ utdanning. Seminar Presentation at the University of Oslo, 18 October. Universitetet i Oslo. 
Helland, H. (2004). Sosial ulikhet blant sosial-og siviløkonomer. Dr. polit.-avhandling, Institutt for sosiologi, Universitetet i Oslo.

Hernes, G. (1974). Om ulikhetens reproduksjon. Hvilken rolle spiller skolen? In S. Mortensen (Ed.), I Forskningens lys. NAVF 25 àr (pp. 231-25l). Lyches forlag.

Hernes, G., \& Knudsen, K. (1976). Levekairsundersøkelsen. Utdanning og ulikhet. NOU 1976:46. Oslo.

Jackson, M., Erikson, R., Goldthorpe, J. H., \& Meir, Y. (2007). Primary and Secondary Effects in Class Differentials in Educational Attainment. The Transition to A-Level Courses in England and Wales. Acta Sociologica, $59(3), 211-229$.

Jonsson, J. O., \& Erikson, R. (2007). Sweden: Why Educational Expansion Is Not Such a Great Strategy for Equality - Theory and Evidence. In Y. Shavit, R. Arum, \& A. Gamoran (Eds.), Stratification in Higher Education. A Comparative Study (pp. 113-139). Stanford University Press.

Kivinen, O., Hedman, J., \& Kaipanen, P. (2007). From Elite to Mass Higher Education. Educational Expansion, Equality of Opportunity and Returns to University Education. Acta Sociologica, 50(3), 231-247.

Kjærnsli, M., \& Jensen, F. (Eds.). (2016). Stø kurs. Norske elevers kompetanse $i$ naturfag, matematikk og lesing i PISA 2015. Universitetsforlaget.

Knudsen, K., Sørensen, A. B., \& Aamodt, P. O. (1993). Endringer $i$ den sosiale rekrutteringen til høyere utdanning etter 1980 (Changes in the Social Recruitment to Higher Education After 1980). Notat, NAVFs Utredningsinstitutt.

Lucas, M. N. (2001). Effectively Maintained Inequality. American Journal of Sociology, 106(6), 1642-1690.

Mare, R. D. (1980). Social Background and School Continuation Decisions. Journal of the American Statistical Association, 75(370), 295-305.

Mare, R. D. (1981). Change and Stability in Educational Stratification. American Sociological Review, 46, 72-87.

Marginson, S. (1998). Competition and Diversity in the Reformed Australian Higher Education System. In L. V. Meek \& F. Q. Wood (Eds.), Managing Higher Education Diversity in a Climate of Public Sector Reform (pp. 81-96). Department of Employment, Education, Training and Youth Affairs.

Marginson, S. (2004). Australian Higher Education: National and Global Markets. In P. Teixeira, B. Jongbloed, D. Dill, \& A. Amaral (Eds.), Markets in Higher Education: Rhetoric or Reality? (pp. 207-240). Kluwer Academic Publishers.

Mincer, J. (1962). On-the-job Training: Costs, Returns and Some Implications. Journal of Political Economy, 70(5), 50-79.

OECD. (2016). OECD Income Distribution Database (IDD). OECD.

Raftery, A. E., \& Hout, M. (1993). Maximally Maintained Inequality: Expansion, Reform and Opportunity in Irish Education, 1921-75. Sociology of Education, $66,41-62$. 
Ramstedt, K. (2009). The Nordic Countries. In T. Matti (Ed.), Northern Lights on PISA 2006. Differences and Similarities in the Nordic Countries. Nordic Council of Ministers.

Schultz, T. (1961). Investment in Human Capital. American Economic Review, $51(5), 1-17$.

Schwarzenberger, A., \& Opheim, V. (2009). Cost-sharing in Higher Education: Differences Between Countries and Between Distinct Socio-Economic Groups. Tertiary Education and Management, 15(2), 157-172.

Shavit, Y., \& Blossfeld, H.-P. (Eds.). (1993). Persistent Inequality. Changing Educational Attainment in Thirteen Countries. Social Inequality Series. Westview Press.

Thomsen, J. P. (2015). Maintaining Inequality Effectively? Access to Higher Education Programmes in a Universalist Welfare State in Periods of Educational Expansion 1984-2010. European Sociological Review, 31(6), 683-696.

Thomsen, J.-P., Bertilsson, E., Dalberg, T., Hedman, J., \& Helland, H. (2017). Higher Education Participation in the Nordic Countries 1985-2010 - A Comparative Perspective. European Sociological Review, 33(1), 98-111.

Tønnesen, L. K. B. (2011). Norsk utdanningshistorie. (Norwegian Education History). Fagbokforlaget.

Vangsnes, S. (1967). Rekrutteringen av artianere og karakterer til Examen artium. En undersøkelse av fire artiumskull. Melding nr. 1, 1967. NAVFs utredningsavdeling.

Open Access This chapter is licensed under the terms of the Creative Commons Attribution 4.0 International License (http://creativecommons.org/licenses/ by $/ 4.0 /$ ), which permits use, sharing, adaptation, distribution and reproduction in any medium or format, as long as you give appropriate credit to the original author(s) and the source, provide a link to the Creative Commons licence and indicate if changes were made.

The images or other third party material in this chapter are included in the chapter's Creative Commons licence, unless indicated otherwise in a credit line to the material. If material is not included in the chapter's Creative Commons licence and your intended use is not permitted by statutory regulation or exceeds the permitted use, you will need to obtain permission directly from the copyright holder.

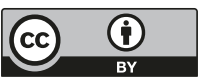

